\title{
O PAPEL DAS EMOÇÕES COMO PREDITORAS DAS ATITUDES E COMPORTAMENTOS DOS INTERNAUTAS NA VIRALIZAÇÃO DE ANÚNCIOS PUBLICITÁRIOS
}

Túlio Marcos ROMANO ${ }^{1}$

\author{
Juliana Maria Magalhães CHRISTINO²
}

\begin{abstract}
${ }^{1}$ Mestre em Administração. Especialista em Marketing. Especialista em Gestão Empresarial. Bacharel em Publicidade e Propaganda. Professor e Diretor Executivo da Universidade Vale do Rio Verde - UninCor. tulio.romano@unincor.edu.br
\end{abstract}

${ }^{2}$ Doutora e Mestre em Administração. Especialista em Marketing. Bacharel em Administração. Professora Adjunta da Universidade Federal de Minas Gerais - UFMG. julianam.prof@gmail.com

Recebido em: 04/05/2016 - Aprovado em: 28/07/2016 - Disponibilizado em: 30/07/2016

\begin{abstract}
RESUMO
A publicidade tem seguido a evolução da Internet como meio de comunicação e comércio aperfeiçoando a integração entre consumidores e fornecedores. Com a popularização das mídias sociais ficou mais evidente o boca-a-boca no ambiente online, onde as pessoas compartilham suas experiências guiadas por estratégias de marketing. Esta pesquisa teve como objetivo investigar o papel das emoções experimentadas pelos internautas em suas atitudes e comportamentos ao compartilharem vídeos virais publicitários com terceiros. Para cumprir o objetivo 309 indivíduos assistiram a três vídeos publicitários de marketing viral extraídos de uma lista dos 10 comerciais brasileiros mais assistidos no portal YouTube em 2012 e responderam a uma pesquisa sobre seus hábitos de acesso e de compartilhamento de vídeos pelo YouTube e as emoções despertadas por estes. Desta forma, além da caracterização demográfica da amostra pesquisada, os resultados revelaram que o compartilhamento dos vídeos ocorre quando estes despertam emoções positivas no espectador, tais como admiração, encantamento e felicidade.
\end{abstract}

Palavras-chave: Emoções. Compartilhamento. Marketing Viral. Publicidade. YouTube.

\begin{abstract}
Advertising has followed the evolution of the Internet as a mean of communication and trade, capable of improving the integration between consumers and suppliers. With the popularity of social media became more evident word-of-mouth in the online environment, where people share their experiences driven by marketing strategies. This research aimed to investigate the role of emotions experienced by Internet users in their attitudes and behaviors to share advertising viral videos with others. To fulfill the objective 309 individuals attended three advertising videos of viral marketing extracted from a list of 10 most watched Brazilian commercial on YouTube portal in 2012 and responded to a survey about their habits and access of video sharing on YouTube and the emotions aroused by these. Thus, in addition to the demographic characteristics of the studied sample, the results revealed that the sharing of videos occurs when these arouse positive emotions in the viewer, such as admiration, delight and happiness.
\end{abstract}

Keywords: Emotions. Sharing. Viral Marketing. Advertising. YouTube.

\section{RESUMEN}

La publicidad ha seguido la evolución de Internet como medio de comunicación y el comercio, capaces de mejorar la integración entre consumidores y proveedores. Con la popularidad de las redes sociales se hizo más evidente boca-aboca en el entorno en línea, donde la gente comparte sus experiencias impulsadas por estrategias de marketing. Esta investigación tuvo como objetivo investigar el papel de las emociones que experimentan los usuarios de Internet en sus actitudes y comportamientos para compartir videos virales de publicidad con los demás. Para cumplir con los objetivos 309 personas asistieron tres videos publicitarios de marketing viral extraído de una lista de 10 más vista comercial brasileña en el portal YouTube en 2012 y respondió a una encuesta sobre sus hábitos y acceso de intercambio de vídeos en YouTube y las emociones despertadas por estos. Por lo tanto, además de las características demográficas de la muestra estudiada, los resultados revelaron que el intercambio de vídeos se produce cuando éstos despiertan emociones positivas en el espectador, como la admiración, alegría y felicidad.

Palabras-clave: Emociones. Compartiendo. Mercadeo Viral. Publicidad. Youtube. 


\section{INTRODUÇÃO}

O compartilhamento de experiências, informações e expectativas pelas páginas da web, através de $b \log s$, fóruns, páginas de mensagens, imagens e vídeos, facilita a comunicação e a troca de ideias que conectam indivíduos e usuários com mesmos interesses. Estas ferramentas recebem o nome de mídias sociais (WEINBERG, 2010).

A temática deste artigo vem despertando interesse no campo da sociometria desde a publicação do trabalho seminal de Granovetter (1973, p. 1361), que apresentou o conceito de "força dos laços": “[...] a força de um laço interpessoal é uma combinação (provavelmente linear) da quantidade de tempo, da intensidade emocional, da intimidade (confiança mútua) e dos serviços recíprocos que a caracterizam." Para este autor, cada um desses fatores age um tanto independentemente dos outros, embora o conjunto seja altamente intercorrelacionado. A principal implicação apresentada por Granovetter em seu artigo é que as experiências pessoais dos indivíduos estariam intimamente ligadas ao aspecto de grande escala da estrutura social, que iria muito além do alcance ou do controle dos indivíduos em particular.

Contemporaneamente, com o crescimento e evolução da Internet, referências eletrônicas de difusão ponto-aponto têm se tornado um importante fenômeno e, segundo De Bruyn \& Lilien (2008), os profissionais de marketing têm tentado explorar seu potencial por meio de campanhas de marketing viral. Ao mesmo tempo, o advento dos spams (e-mails não solicitados difundidos em massa) e de mensagens eletrônicas contendo vírus vem dificultando a comunicação eletrônica, tornando problemáticas as campanhas de marketing viral e desafiando a sua implementação.

Este artigo busca estudar o tipo e o papel das emoções experimentadas pelos internautas em suas atitudes e intenções comportamentais na viralização de anúncios publicitários, verificando a intensidade das emoções em relação às atitudes dos internautas no que diz respeito às marcas, aos anúncios e à propensão em compartilhá-los.

$\mathrm{O}$ presente estudo se justifica pela importância estratégica do tema na atualidade, quando as mídias tradicionais já não têm o mesmo efeito de antigamente. $\mathrm{O}$ consumidor ainda é acossado e alimentado por distorções e tentativas padronizadas de influenciá-lo, porém ele é cético com a publicidade de massa e as promessas dos fornecedores. Outro fator motivador para este estudo é a falta de pesquisas aplicadas sobre este tema no cenário nacional. Considerando a crescente importância do Brasil como um mercado emergente, as empresas que atuam no mercado publicitário precisam compreender melhor a alocação de recursos entre as 
estratégias de comunicação utilizadas (VENKATESAN et al., 2012; SHETH, 2011). Isso gera uma oportunidade considerável para acadêmicos no sentido de investigarem as aplicações do marketing viral em empresas ou em produtos e serviços disponíveis no Brasil, bem como propor novas técnicas para avaliar a aplicação dessa estratégia nas redes sociais.

\section{TEORIA E FUNÇÕES DA EMOÇÃO}

Pouca consistência pode ser encontrada no uso da terminologia relacionada ao fenômeno das emoções. Para organizar a discussão neste artigo, começaremos com uma definição de emoção e de conceitos correlatos.

\subsection{Definições}

O termo "afetar" será utilizado neste trabalho como um guarda-chuva para denominar um conjunto mais específico de processos mentais, incluindo emoções, humores e (possivelmente) atitudes. Assim, "afetar" pode ser considerada uma categoria geral para processos que envolvam sentimentos mentais, ao invés de se constituir em um processo psicológico específico, por si só.

De acordo com Bagozzi, Gopinath \& Nyer (1999) entende-se por emoção um estado mental de alerta que surge da avaliação cognitiva de eventos ou de pensamentos; emoções são acompanhadas por processos fisiológicos e, frequentemente, se expressam fisicamente (por exemplo: em gestos, posturas e características faciais); podendo resultar em ações específicas para afirmar ou lidar com a emoção, dependendo da natureza e significado que esta possa assumir para cada indivíduo. O limite entre uma emoção e um estado de espírito é frequentemente difícil de se estabelecer, mas muitas vezes, convenciona-se conceber um estado de espírito como sendo mais duradouro, porém de menor intensidade do que uma emoção. No entanto, exceções a esta interpretação podem ser encontradas. Outra distinção, ainda, entre emoções e humores, ou estados de espírito, é que a emoção normalmente é intencional, ou seja, tem um objeto ou referência. Considerando que estados de espírito são geralmente não-intencionais e globais ou difusos, também não são acoplados diretamente a tendências a agir e a ações explícitas como são muitas das emoções.

Consequentemente, as atitudes, também, são muitas vezes consideradas estágios dos estados de espírito, com as mesmas medidas utilizadas, em algumas ocasiões, para indicar as emoções e atitudes, por exemplo: agradável-desagradável, feliztriste, ou itens com diferenciais semânticos, ex: interessado-desinteressado. No entanto, alguns autores têm uma visão mais estreita do conceito de atitude e o definem como um 
julgamento avaliativo medido, por exemplo, por reações boas ou más ao invés de considerar este conceito como um estado emocional. Cohen \& Areni (1991), por exemplo, preferem definir o termo estado de espírito ou "humor" por "estados validados de sentimentos" e atitudes são, na visão destes autores, julgamentos avaliativos.

Segundo Bagozzi, Gopinath \& Nyer (1999, p. 185), provavelmente o fator mais importante que diferencia o conceito de emoção das noções de estados de espírito e atitudes é a forma como as emoções surgem. Emoções, como já mencionado, têm um alvoreferência específico, por exemplo, um consumidor fica satisfeito quando um novo detergente remove manchas difíceis, ou fica indignado com o mau serviço de um restaurante. Especificamente, emoções surgem em resposta a avaliações feitas sobre algo relevante para o bem-estar. Por "avaliação" entenda-se um julgamento avaliativo de algo e a sua interpretação. Por "relevante" entenda-se um incidente ou episódio que acontece por si mesmo, em geral, um evento não-planejado. É importante salientar que as categorias de eventos e circunstâncias físicas se encontram frequentemente associadas a respostas emocionais particulares. Não são os eventos específicos ou as circunstâncias físicas que produzem as emoções, mas aquela avaliação psicológica única feita pelo indivíduo envolvido ao julgar e interpretar os acontecimentos e circunstâncias. Diferentes pessoas podem ter reações emocionais diversas para um mesmo evento ou acontecimento, ou mesmo não ter reação emocional alguma. Observe-se também que avaliações podem ser deliberadas, propositais e conscientes, dependendo da pessoa, mas também: irrefletidas, automáticas e inconscientes e suscitar condições de excitação emocional.

Teóricos que estudam o fenômeno da avaliação afirmam que o determinante crítico de qualquer emoção é a avaliação resultante e a interpretação que surgem após a comparação entre um estado real e o desejado. Duas avaliações são particularmente cruciais nesta fase de formação de uma emoção: relevância do objetivo e congruência deste (LAZARUS, 1991).

De acordo com Oatley \& JohnsonLaird (1987), as emoções são evocadas "em um momento significativo de um plano... normalmente... quando a avaliação (consciente ou inconsciente) do provável sucesso de um plano muda" (p. 35). Emoções positivas, por exemplo: felicidade, alegria, júbilo, estão associadas à realização de um objetivo, que, geralmente, leva a uma decisão de continuar com o plano, ao passo que as emoções negativas, por exemplo: frustração, decepção, ansiedade, resultam de problemas com planos em andamento e falhas para atingir as metas desejadas. 
Profissionais de marketing tendem a adotar uma abordagem empírica para medir emoções relacionadas à avaliação de peças publicitárias. Isto já é feito há muito tempo. Burke \& Edell (1989) desenvolveram uma escala com 52 itens para medir as emoções experimentadas em relação a propagandas assistidas e Edell \& Burke (1987); Holbrook \& Batra (1990) analisaram itens na mencionada escala e encontraram três fatores: sentimentos otimistas, sentimentos pessimistas e sentimentos calorosos.

A quantidade de itens diferentes investigados, nesse sentido, pode atingir a 180 (AAKER, STAYMAN \& VEZINA, 1988) enquanto que, usando-se outra técnica, basicamente, um único item pode ser medido continuamente enquanto o público pesquisado assiste a um anúncio.

\section{MARKETING VIRAL}

A publicidade provoca emoções nos indivíduos, impulsiona seus desejos latentes, os quais os impedem de fazer qualquer coisa, a não ser satisfazê-los. Ela atua de forma individual ou em grupo, cada um dos indivíduos que integram um grupo adquire, então, uma psicologia diferente daquela de quando se encontrava isolado e age como se o próprio grupo fosse constituído por leis psicológicas particulares (SANT`ANNA et al., 2009).
O apelo emocional na publicidade refere-se, ainda, aos valores pessoais, ou seja, aquilo que se busca promover no consumidor, a saber: familiaridade, aproximação e confiança. É por esse caminho que percorre o discurso publicitário com suas características persuasiva, argumentativa e manipuladora, que, por meio de discursos icônicoslinguísticos influenciam o consumidor em seu comportamento, fazendo-o anuir à mensagem (MONNERAT, 2003).

Com o avanço tecnológico, as alterações culturais, comportamentais e as perspectivas geradas pelas mídias digitais mudaram a forma como o consumidor enxerga a publicidade. Começaram a exigir uma maior interatividade entre os meios, principalmente com o surgimento da Internet, passando o público-alvo a ficar interconectado e uma das estratégias que publicitários estão utilizando no ambiente digital para atrair a atenção desse consumidor é o marketing viral. (BARICHELLO; OLIVEIRA, 2010).

Para essas duas autoras o conceito de “marketing viral” está associado à ideia de divulgação de uma mensagem publicitária, enquanto que viral é uma metáfora que resulta do processo biológico da transmissão de um vírus que vai se alastrando de indivíduo para indivíduo. $\mathrm{O}$ marketing viral seria então a transmissão da mensagem publicitária de internauta para internauta em um ambiente digital. Assim, essa propagação deve 
acontecer em grande escala de forma intensa e colaborativa dos indivíduos, em grande parte das vezes em redes sociais. Dessa maneira atua como uma ferramenta estratégica de marketing atraindo a atenção e o interesse do consumidor, tornando-se um elemento de divulgação e venda, alterando-o da situação de ser apenas um receptor passivo da mensagem para um status de emissor ativo influenciando sua rede de contatos sociais online.

O marketing viral tem sido também descrito como "o processo de atrair clientes repassando uma mensagem de marketing de uma empresa para os amigos, família e colegas" (LAUDON \& TRAVER, 2001, p. 381). Como um vírus, informações sobre a empresa e sua marca, bens ou serviços são espalhados a potenciais compradores, que, em seguida, repassam a informação a outros compradores potenciais de tal forma que uma enorme rede é criada rapidamente (DOBELE et al. 2005; LINDGREEN \& VANHAMME, 2005). O marketing viral ganhou enorme popularidade com a introdução dos meios eletrônicos facilitando as interconexões entre empresas e potenciais consumidores (GRUEN, OSMONBEKOV \&

\section{CZAPLEWSKI, 2006).}

Subramani e Rajagopalan (2003, p. 300) definem, ainda, marketing viral como "a tática de criar um processo pelo qual pessoas interessadas envolvem outras", mas alertam para diferenças com o processo de boca-a- boca pessoal por não envolver o contato facea-face. A distinção entre o boca-a-boca convencional e o marketing viral também é destacada por Modzelewski (2000), ao advertir que "o valor do vírus para o consumidor original é diretamente relacionado com o número de outros usuários que ele atrai, isto é, o originador de cada ramificação do vírus tem um interesse exclusivo e dedicado em recrutar novas pessoas para a rede”. Barret (2001), por sua vez, define marketing viral como "a disseminação deliberada de mensagens por meio do boca-a-boca eletrônico". Nesta ação, mensagens promocionais são elaboradas por practitioners do marketing e disponibilizadas por meio de links de Internet ou enviadas para uma base de usuários potenciais ou de clientes cadastrados com o propósito de criar uma progressão geométrica na sua disseminação, ampliando o alcance e a cobertura do mercado a um custo muito inferior do que o de uma campanha tradicional de marketing.

Apesar do fato de que o marketing viral pode ser um meio bem-sucedido de comunicação de marketing, ainda há uma compreensão limitada sobre como ele funciona (BORROFF, 2000; BRODIN, 2000; HELM, 2000). As campanhas de marketing viral podem resultar em recomendações bocaa-boca ou buzz (bochicho), aumentando assim a credibilidade da mensagem marketing viral pode impulsionar as vendas, reduzir custos de marketing e chegar aos consumidores 
cansados das mídias tradicionais. Nesse sentido, é vital que as empresas escolham cuidadosamente quais os consumidores que deverão ser impactados pelas mensagens virais, pois a criação das redes depende desses consumidores (HELM, 2000).

As motivações para que se encaminhe uma mensagem viral não podem ser totalmente analisadas sem se considerar o conteúdo da própria mensagem e suas características específicas. O sucesso viral depende da participação ativa dos consumidores no encaminhamento de mensagens para terceiros, de modo que as campanhas são muitas vezes mais impactadas pelo fator emocional da mensagem do que propriamente pelo produto ou serviço que se está divulgando (ECKLER \& BOLLS, 2011).

Para ocorrer uma campanha bem sucedida de marketing viral, deve haver algo único e poderoso na mensagem, algo que incentive o consumidor a passá-la adiante. As emoções são fenômenos que levam os consumidores a compartilharem as mensagens de marketing viral (DOBELLE et al, 2007).

As mensagens das campanhas de marketing viral devem construir uma conexão emocional entre a campanha e o destinatário, assegurando que o "vírus" se propague. A emoção de uma mensagem é o que provavelmente leva o consumidor à ação, vídeos virais muitas vezes utilizam os fatores emocionais como recursos de persuasão. Pesquisas anteriores descobriram que os anúncios virais confiam mais em apelos relacionados com humor, sexualidade, nudez e violência do que os anúncios de televisão tradicionais (PORTER \& GOLAN, 2006).

Lindgreen \& Vanhamme (2005, p.125) afirmam que "emoções são motores essenciais de campanhas de marketing viral" e que o fator surpresa é uma importante emoção para o sucesso viral. A emoção surpresa é uma forte influência sobre o comportamento na condução das campanhas de marketing viral (DERBAIX \& VANHAMME, 2003). A surpresa é, no entanto, apenas um das seis emoções primárias, as outras cinco são: medo, tristeza, alegria, nojo e raiva (OATLEY \& JENKINS, 1996).

Anunciantes virais esperam associar instantaneamente um bom sentimento experimentado pelo receptor da mensagem ao receber um conteúdo provocativo. Além disso, enquanto que a publicidade tradicional é definida como a comunicação geral, o conteúdo provocativo é também parte da equação para o sucesso do marketing viral. Anunciantes virais fazem com que o conteúdo seja emocional ou engraçado para os indivíduos-alvos o suficiente para justificar que estes o repassem para outros usuários (PORTER \& GOLAN, 2006). 


\section{O PROBLEMA DE PESQUISA}

De que maneira as emoções interferem na propensão dos internautas em compartilharem com terceiros nas redes sociais as mensagens veiculadas por filmes publicitários do YouTube?

\subsection{Objetivo geral}

Investigar como as emoções despertadas pelas mensagens contidas nos temas veiculados em filmes publicitários do YouTube interferem na propensão dos internautas em compartilhá-los com terceiros nas redes sociais.

\subsection{Objetivos específicos}

$1^{\text {o }}$ - Ranquear quantitativamente em ordem decrescente as principais emoções sentidas pelos entrevistados ao assistirem aos vídeos selecionados;

$2^{\circ}$ - Identificar quais as principais emoções motivadoras para que se repasse um determinado vídeo adiante.

\section{METODOLOGIA}

Com o propósito de responder ao questionamento do problema de pesquisa, foram utilizados três vídeos como estímulo, escolhidos a partir de uma lista publicada pelo site especializado em vídeos de marketing viral Brainstorm9 (2013), onde se encontrou uma lista com 10 comerciais brasileiros mais virais vistos no YouTube em 2012.

Logo após assistirem aos vídeos, os entrevistados responderam a questionários estruturados compostos por quesitos de múltipla-escolha cujas opções de resposta se encontravam em uma escala tipo Likert com cinco pontos. Para o desenvolvimento do questionário buscou-se compreender os níveis de envolvimento do internauta em viralizar vídeos publicitários e quais as emoções o afetariam para isso em relação à marca e ao anúncio.

É importante ressaltar que a amostra inquirida provinha de uma população predominantemente composta pela Geração Y, cujos hábitos são fortemente influenciados pela Internet, fazendo deste público um dos principais segmentos-alvo do marketing viral (KINLEY, JOSIAM \& LOCKETT, 2010).

Os três vídeos assistidos pelos respondentes da pesquisa foram:

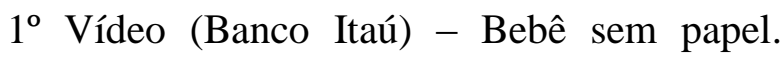
Disponível em: <http://www.YouTube.com/watch?v=p9Z9n0I 8Dfo>. Acesso em: 11 de set. 2013. Com mais de 15 milhões de visualizações, o vídeo apresenta uma campanha publicitária, nela o Banco Itaú fala da importância de se economizar papel acessando o extrato pelo site. Para isso, o banco utilizou um vídeo viral 
onde um bebê dá uma gargalhada toda vez que o papel é rasgado.

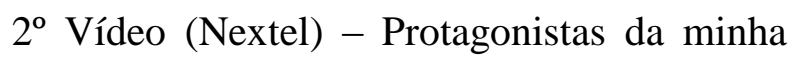
história. Disponível em: <http://www.YouTube.com/watch?v=a3hmM $\underline{\mathrm{K}-\mathrm{ukBU}>}>$. Acesso em: 11 de set. 2013. Com cerca de 10 milhões de acessos a Nextel apresenta um vídeo no qual o atleta de vôlei Ricardinho faz uma surpresa para sua família enaltecendo a importância desta nos momentos mais difíceis de sua carreira.

$3^{\mathrm{o}}$ Vídeo (Budweiser) - The Great Preparation. Disponível em: <http://www.YouTube.com/watch?v=4hUDU $\underline{\text { U2GD6I> }}$. Acesso em: 11 de set. 2013. Com mais de 11 milhões de visualizações, este vídeo da Budwiser conta com o lutador de brasileiro Anderson Silva e com o ator Steven Seagal em sua preparação para mais um desafio.

\subsection{A amostra da pesquisa}

Foram coletados dados de um total de 347 indivíduos, sendo que foram excluídas as respostas de 38 respondentes por apresentarem mais de $10 \%$ de dados ausentes. Dessa forma, a análise foi conduzida com as respostas de 309 indivíduos, sendo que desses, 89 apresentaram, pelo menos, uma das observações ausentes. O método de amostragem empregado foi o não- probabilístico e os elementos amostrais selecionados por conveniência. A base de respondentes do estudo foi composta por estudantes de graduação de uma universidade privada situada no Sul do Estado de Minas Gerais, porém, pelo fato de não se ter utilizado uma amostragem probabilística, quaisquer extrapolações e inferências dos resultados para o conjunto da população como um todo com as mesmas características deverão ser feitas com extrema cautela.

\subsection{Procedimentos preparatórios nos dados} antes da análise estatística

Por ser considerada mais adequada, a codificação das opções de resposta na escala Likert original, anteriormente variando entre 1 $-2-3-4-5$ foi transformada para: (-) $1-$ (-) $0,5-0-(+) 0,5-(+) 1$, sendo que os valores positivos indicam pontuações maiores que 3, ou seja, o ponto médio na escala Likert original e os valores negativos indicam pontuações menores que 3 na mesma escala. Assim, os valores positivos na escala transformada significam que os respondentes tendiam a concordar com aqueles itens, enquanto que valores negativos indicam que os respondentes tendiam a discordar daqueles itens. Para as escalas transformadas foram calculadas a média e o intervalo percentílico bootstrap com $95 \%$ de confiança. O método bootstrap (EFRON \& TIBSHIRANI, 1993) é utilizado na realização de inferências quando 
se desconhece a distribuição de probabilidades da variável que se deseja estudar.

Para representar os construtos: intensidade das emoções, intensidade do envolvimento, atitude em relação à marca, atitude em relação ao anúncio e propensão a compartilhar o vídeo, foi criado um índice a partir da padronização dos escores retornados pela análise fatorial em uma escala variando de 0 a 100, de acordo com a fórmula:

$$
\text { Índice Padronizado }=100 x \frac{\text { Escore }- \text { mínimo(Escore })}{\text { máximo(Escore })- \text { mínimo(Escore })}
$$

Ao criarmos um índice a partir da Análise Fatorial, é importante primeiramente verificar a adequação da solução fatorial através do teste Kaiser-Meyer-Olkin (KMO), uma estatística que indica a proporção da variância dos dados que pode ser considerada comum a todas as variáveis, ou seja, que pode ser atribuída a um fator comum, então: quão mais próximo de 1 (unidade) melhor $\mathrm{o}$ resultado, ou seja, mais adequada é a amostra à aplicação da análise fatorial. De acordo com (HAIR, Jr. et al. 2009), para se utilizar a Análise Fatorial, o teste KMO deve retornar com um valor acima de 0,50. De forma a identificar a dimensionalidade de cada construto, foi utilizado o critério de Kaiser (MINGOTI, 2007). Esse critério retorna o número de fatores que devem ser retidos em uma Análise Fatorial, ou seja, a quantidade de dimensões do construto. A qualidade do ajuste fatorial foi verificada pela variância explicada (VE), sendo que, de acordo com (HAIR, Jr. et al. 2009), valores acima de 50\% indicam um bom ajuste. A avaliação do grau de consistência entre as múltiplas medidas de cada construto foi efetuada pelo Alfa de Cronbach que, de acordo com (HAIR, Jr. et al. 2009), baliza-se pelo valor mínimo de 0,70 .

De modo a verificar se os índices criados eram estatisticamente diferentes entre os vídeos publicitários do Itaú, da Nextel e da Budweiser, foram realizados testes de Friedman (HOLLANDER \& WOLFE, 1999), sendo posteriormente efetuadas as comparações múltiplas pelo teste WilcoxonNemenyi-McDonald-Thompson (HOLLANDER \& WOLFE, 1999).

A fim de se verificar que fatores influenciam o índice de compartilhamento foi utilizada a Análise de Regressão via QuaseVerosimilhança (WEDDERBURN, 1974; McCULLAGH \& NELDER, 1989) com função de variância constante e de ligação identidade. O método da QuaseVerossimilhança é muito utilizado por prescindir de suposições distribucionais, sendo necessário apenas especificar a estrutura da média e da variância. Como a estrutura da média, definida pela função de 
ligação, foi a identidade, denomina-se a regressão como linear. Para selecionar as variáveis significativas para explicar a variabilidade do índice de compartilhamento, foi empregado o algoritmo de seleção Stepwise (EFROYMSON, 1960).

O Stepwise é um dos métodos mais utilizados para seleção de variáveis no contexto de uma análise de regressão, pode-se defini-lo como uma mescla dos métodos Backward e Forward. Para o método Foward (critério de entrada das variáveis na análise de regressão multivariada) foram utilizadas regressões lineares univariadas, sendo adotado um nível de significância de $25 \%$. As variáveis selecionadas entraram na regressão linear multivariada, sendo aplicado nessa etapa o método Backward, que é o procedimento de retirar, uma a uma, a variável de maior p-valor, sendo esse procedimento repetido até que restem no modelo somente variáveis significativas. Para o método Backward foi adotado um nível de 5\% de significância. Denomina-se a regressão final para o índice de compartilhamento, após o procedimento Backward e Forward como Regressão Linear Stepwise.

\section{ANÁLISE E DISCUSSÃO DOS RESULTADOS}

A pesquisa desenvolvida foi do tipo descritivo-conclusivo e a metodologia centrada na análise quantitativa de dados. $\mathrm{O}$ estudo envolveu o uso de técnicas estatísticas uni e multivariadas.

\subsection{Perfil demográfico dos respondentes da pesquisa}

Do total de 309 estudantes cujas respostas foram consideradas válidas, $62,1 \%$ (192 elementos) pertenciam ao gênero masculino; a faixa etária predominante foi "de 17 até 25 anos", 84,4\% (260); o estado civil mais ocorrente foi "solteiro", 86,5\% (262); a faixa de "renda mensal familiar" mais incidente declarada à época da coleta dos dados (Nov/Dez/2013) foi "mais de R\$ $1.500,00$ até $\mathrm{R} \$ 3.000,00 \%, 35,5 \%$ (99), seguida por "mais de $\mathrm{R} \$ 600,00$ até $\mathrm{R} \$$ 1500,00", 31,5\% (88).

Dessa forma, resumindo, os respondentes eram predominantemente do gênero masculino, solteiros e com renda mensal familiar relativamente baixa, o que deve ser levado em conta na análise dos resultados.

\subsection{Características do acesso ao YouTube}

Inicialmente foi levantado o perfil dos usuários do YouTube que compunham a amostra. 57,0\% concordaram "em parte" ou "totalmente" que eram apenas "espectadores", ou seja, somente assistiam aos vídeos cujos links lhes eram enviados por terceiros. Somente o percentual de $12,4 \%$ concordou 
"em parte" ou "totalmente" que eram "participantes", isto é, interagiam com outros internautas e compartilhavam os links com os conteúdos dos vídeos postados no YouTube e uma parcela menor ainda $(6,5 \%)$ informou "em parte" ou "totalmente" que pertencia à categoria dos "criadores", ou seja, que desenvolviam seus próprios vídeos e os divulgavam na Internet.

O segundo fator levantado foi "frequência de acesso" ao YouTube, que apresentou uma distribuição praticamente equitativa dos resultados, isto é, 40,1\% dos respondentes declararam acessar "muito" ou "quase muito"; 30,4\% informaram não acessar "nem pouco, nem muito" e 29,4\% disseram acessar "pouco" ou "mais que um pouco" aquele serviço de divulgação e de compartilhamento de vídeos.

A característica seguinte foi "o indivíduo deter conhecimentos para compartilhar vídeos nas redes sociais". 53,7\% dos respondentes informaram saber compartilhar "muito" ou "quase muito", ao passo que 33,4\% declararam saber compartilhar "pouco" ou "mais que um pouco" e apenas $12,8 \%$ informaram não saber compartilhar "nem pouco, nem muito".

Em seguida foi avaliado com que intensidade os respondentes compartilhavam efetivamente vídeos nas redes sociais e os resultados indicaram que apenas $18,5 \%$ informaram compartilhar "muito" ou "quase muito", 18,9\% não compartilhavam "nem pouco, nem muito" e a maioria, 62,6\%, compartilhava "pouco" ou "mais que um pouco".

Quanto às opções de local de acesso ao YouTube, apenas 8,7\% informaram acessar "muito" ou "quase muito" no trabalho; 52,5\% declararam acessar "muito" ou "quase muito" em casa e somente 9,2\% informaram acessar "muito" ou "quase muito" nos computadores do estabelecimento de ensino que frequentavam.

No tocante aos tipos de conteúdo acessados no YouTube e intensidade de acesso, informaram acessar "muito" ou "quase muito" as seguintes categorias de vídeos: (42,3\%) filmes de ficção; (25,9\%) noticiários; $(23,2 \%)$ documentários; $(22,9 \%)$ esportes; $(21,9 \%)$ programas de TV; $(19,8 \%)$ vídeos virais; $(12,1 \%)$ propaganda e $(6,0 \%)$ vídeos pornográficos.

\subsection{Emoções sentidas por quem assistiu aos três vídeos no YouTube}

Esta pesquisa se baseou nos cinco tipos de emoções primárias identificados no trabalho de Dobele et al. (2007) os quais foram desdobrados em orientações positivas e negativas, ex: feliz/infeliz e acrescentadas outras emoções até perfazerem dezoito. 
Tabela 01 - Como o respondente se sentiu após assistir aos vídeos.

\begin{tabular}{|c|c|c|c|c|c|c|c|c|c|}
\hline \multirow{3}{*}{ Variáveis } & \multicolumn{3}{|c|}{ ITAÚ } & \multicolumn{3}{|c|}{ NEXTEL } & \multicolumn{3}{|c|}{ BUDWEISER } \\
\hline & \multirow{2}{*}{ Média } & \multicolumn{2}{|c|}{ I.C $-95 \%$} & \multirow{2}{*}{ Média } & \multicolumn{2}{|c|}{ I.C $-95 \%$} & \multirow{2}{*}{ Média } & \multicolumn{2}{|c|}{ I.C - 95\% } \\
\hline & & L.I. & L.S. & & L.I. & L.S. & & L.I. & L.S. \\
\hline Admirado & 0,22 & 0,16 & 0,28 & 0,39 & 0,33 & 0,45 & 0,02 & $-0,04$ & 0,08 \\
\hline Alegre & 0,49 & 0,43 & 0,54 & 0,23 & 0,17 & 0,29 & 0,11 & 0,04 & 0,17 \\
\hline Angustiado & $-0,76$ & $-0,81$ & $-0,72$ & $-0,55$ & $-0,60$ & $-0,49$ & $-0,57$ & $-0,62$ & $-0,51$ \\
\hline Assustado & $-0,79$ & $-0,83$ & $-0,75$ & $-0,71$ & $-0,75$ & $-0,66$ & $-0,61$ & $-0,66$ & $-0,56$ \\
\hline Com Aversão & $-0,74$ & $-0,79$ & $-0,70$ & $-0,69$ & $-0,73$ & $-0,64$ & $-0,63$ & $-0,68$ & $-0,58$ \\
\hline Com Desgosto & $-0,81$ & $-0,85$ & $-0,77$ & $-0,74$ & $-0,78$ & $-0,69$ & $-0,65$ & $-0,70$ & $-0,60$ \\
\hline Com medo & $-0,84$ & $-0,87$ & $-0,79$ & $-0,78$ & $-0,82$ & $-0,74$ & $-0,69$ & $-0,74$ & $-0,65$ \\
\hline Com raiva & $-0,85$ & $-0,88$ & $-0,81$ & $-0,77$ & $-0,81$ & $-0,72$ & $-0,66$ & $-0,71$ & $-0,60$ \\
\hline Com repugnância & $-0,81$ & $-0,85$ & $-0,77$ & $-0,73$ & $-0,78$ & $-0,69$ & $-0,68$ & $-0,73$ & $-0,63$ \\
\hline Encantado & 0,31 & 0,24 & 0,37 & 0,26 & 0,20 & 0,32 & $-0,23$ & $-0,29$ & $-0,16$ \\
\hline Enfurecido & $-0,81$ & $-0,85$ & $-0,76$ & $-0,74$ & $-0,79$ & $-0,70$ & $-0,64$ & $-0,69$ & $-0,59$ \\
\hline Feliz & 0,43 & 0,37 & 0,49 & 0,29 & 0,24 & 0,35 & 0,01 & $-0,05$ & 0,07 \\
\hline Infeliz & $-0,84$ & $-0,87$ & $-0,80$ & $-0,74$ & $-0,79$ & $-0,69$ & $-0,65$ & $-0,70$ & $-0,60$ \\
\hline Irritado & $-0,84$ & $-0,88$ & $-0,80$ & $-0,75$ & $-0,80$ & $-0,70$ & $-0,63$ & $-0,68$ & $-0,57$ \\
\hline Maravilhado & 0,14 & 0,08 & 0,21 & 0,26 & 0,19 & 0,32 & $-0,17$ & $-0,24$ & $-0,11$ \\
\hline Surpreso & $-0,13$ & $-0,20$ & $-0,06$ & 0,11 & 0,04 & 0,18 & $-0,07$ & $-0,14$ & 0,00 \\
\hline Temeroso & $-0,75$ & $-0,80$ & $-0,71$ & $-0,71$ & $-0,75$ & $-0,66$ & $-0,64$ & $-0,69$ & $-0,58$ \\
\hline Triste & $-0,87$ & $-0,90$ & $-0,83$ & $-0,73$ & $-0,78$ & $-0,68$ & $-0,68$ & $-0,73$ & $-0,63$ \\
\hline
\end{tabular}

Fonte - Dados da pesquisa. Processamento efetuado por meio do Software Estatístico R, Versão 3.0.1.

I.C. Intervalo de confiança - L.I. Limite inferior - L.S. Limite superior.

Ao se analisar os resultados foram encontrados dois subconstrutos referentes à intensidade das emoções denominadas "Positivas" e "Negativas". Conforme se observa na Tabela 01, as emoções com médias positivas predominantes despertadas nos espectadores dos vídeos foram:

ITAÚ: Em média, segundo as emoções listadas, os indivíduos concordaram em terem se sentido: Admirados, Alegres, Encantados, Felizes e Maravilhados e discordaram de terem sentido as demais emoções.

NEXTEL: Em média, segundo as emoções listadas, os indivíduos concordaram em terem se sentido: Admirados, Alegres, Encantados,
Felizes, Maravilhados e Surpresos e discordaram de terem sentido as demais emoções.

BUDWEISER: Em média, segundo as emoções listadas, os indivíduos concordaram em terem se sentido Alegres. Ficaram em dúvida ou nem concordaram ou discordaram em terem se sentido: Admirados e Felizes e discordaram de terem sentido as demais emoções.

Na Tabela 02 a seguir, tem-se a média e o intervalo de $95 \%$ de confiança para o nível de concordância sobre como os respondentes da pesquisa se sentem a respeito da empresa anunciante. De uma forma geral, os 
indivíduos tendem a discordar de todas as afirmações referentes às três empresas anunciantes, ou seja, não se observa um vínculo emocional dos indivíduos com elas, uma vez que todas as médias apresentaram valores negativos.

Tabela 02 - média e intervalo de $95 \%$ de confiança para o nível de concordância sobre como os respondentes se sentem a respeito da empresa anunciante.

\begin{tabular}{|c|c|c|c|c|c|c|c|c|c|}
\hline \multirow{3}{*}{ Variáveis } & \multicolumn{3}{|c|}{ ITAÚ } & \multicolumn{3}{|c|}{ NEXTEL } & \multicolumn{3}{|c|}{ BUDWEISER } \\
\hline & \multirow{2}{*}{ Média } & \multicolumn{2}{|c|}{ I.C $-95 \%$} & \multirow{2}{*}{ Média } & \multicolumn{2}{|c|}{ I.C - $95 \%$} & \multirow{2}{*}{ Média } & \multicolumn{2}{|c|}{ I.C - 95\% } \\
\hline & & L.I. & L.S. & & L.I. & L.S. & & L.I. & L.S. \\
\hline É muito importante pra mim & $-0,31$ & $-0,37$ & $-0,25$ & $-0,46$ & $-0,51$ & $-0,40$ & $-0,21$ & $-0,28$ & $-0,14$ \\
\hline Significa muito pra mim & $-0,39$ & $-0,44$ & $-0,33$ & $-0,49$ & $-0,54$ & $-0,44$ & $-0,27$ & $-0,34$ & $-0,20$ \\
\hline Eu tenho muito interesse pela empresa & $-0,30$ & $-0,36$ & $-0,24$ & $-0,36$ & $-0,43$ & $-0,30$ & $-0,15$ & $-0,22$ & $-0,08$ \\
\hline A empresa é muito relevante pra mim & $-0,28$ & $-0,34$ & $-0,22$ & $-0,39$ & $-0,44$ & $-0,34$ & $-0,24$ & $-0,31$ & $-0,17$ \\
\hline $\begin{array}{l}\text { Eu fico chateado/entediado quando } \\
\text { outras pessoas falam da empresa }\end{array}$ & $-0,39$ & $-0,45$ & $-0,34$ & $-0,44$ & $-0,50$ & $-0,39$ & $-0,43$ & $-0,49$ & $-0,37$ \\
\hline
\end{tabular}

Fonte - Dados da pesquisa. Processamento efetuado por meio do Software Estatístico R, Versão 3.0.1.

Na Tabela 03 a seguir, tem-se a média e o intervalo de $95 \%$ de confiança para a atitude dos respondentes da pesquisa em relação à marca.

Tabela 03 - média e intervalo de 95\% de confiança para a atitude dos respondentes em relação à marca.

\begin{tabular}{|c|c|c|c|c|c|c|c|c|c|}
\hline \multirow{3}{*}{ Variáveis } & \multicolumn{3}{|c|}{ ITAÚ } & \multicolumn{3}{|c|}{ NEXTEL } & \multicolumn{3}{|c|}{ BUDWEISER } \\
\hline & \multirow{2}{*}{ Média } & \multicolumn{2}{|c|}{ I.C $-95 \%$} & \multirow{2}{*}{ Média } & \multicolumn{2}{|c|}{ I.C - 95\% } & \multirow{2}{*}{ Média } & \multicolumn{2}{|c|}{ I.C $-95 \%$} \\
\hline & & L.I. & L.S. & & L.I. & L.S. & & L.I. & L.S. \\
\hline Ruim - Boa & 0,14 & 0,07 & 0,21 & 0,14 & 0,07 & 0,20 & 0,27 & 0,20 & 0,34 \\
\hline Negativa - Positiva & 0,06 & $-0,02$ & 0,13 & 0,07 & 0,01 & 0,14 & 0,17 & 0,09 & 0,24 \\
\hline Desfavorável - Favorável & 0,02 & $-0,05$ & 0,09 & 0,08 & 0,01 & 0,14 & 0,14 & 0,07 & 0,22 \\
\hline Não Gosto - Gosto & 0,04 & $-0,03$ & 0,12 & 0,04 & $-0,03$ & 0,10 & 0,16 & 0,08 & 0,24 \\
\hline
\end{tabular}

Fonte - Dados da pesquisa. Processamento efetuado por meio do Software Estatístico R, Versão 3.0.1.

ITAÚ: Em média, pode-se afirmar que a empresa anunciante possui uma boa marca, porém os respondentes têm dúvidas quanto à imagem negativa ou positiva, se ela é desfavorável ou favorável e se gostam ou não da marca, uma vez que os intervalos de confiança cruzam o valor zero.

NEXTEL: Em média, pode-se afirmar que a empresa anunciante possui uma boa marca, tem uma imagem positiva e favorável, porém os respondentes têm dúvidas se gostam ou não da marca, uma vez que os intervalos de confiança também cruzam o valor zero.

BUDWEISER: Em média, pode-se afirmar que a empresa anunciante possui uma boa marca, tem uma imagem positiva, favorável e os respondentes gostam da marca.

Na Tabela 04 a seguir, tem-se a média e o intervalo de $95 \%$ de confiança para atitude dos respondentes em relação aos 
vídeos de propaganda das três empresas.

As avaliações foram em média positivas para os três vídeos, ou seja, os respondentes tenderam a avaliar como boa, positiva ou favorável e que gostaram dos três vídeos apresentados

Tabela 04 - média e intervalo de 95\% de confiança para a atitude dos respondentes em relação ao vídeo de propaganda de cada empresa.

\begin{tabular}{|c|c|c|c|c|c|c|c|c|c|}
\hline \multirow{3}{*}{ Variáveis } & \multicolumn{3}{|c|}{ ITAÚ } & \multicolumn{3}{|c|}{ NEXTEL } & \multicolumn{3}{|c|}{ BUDWEISER } \\
\hline & \multirow{2}{*}{ Média } & \multicolumn{2}{|c|}{ I.C $-95 \%$} & \multirow{2}{*}{ Média } & \multicolumn{2}{|c|}{ I.C $-95 \%$} & \multirow{2}{*}{ Média } & \multicolumn{2}{|c|}{ I.C $-95 \%$} \\
\hline & & L.I. & L.S. & & L.I. & L.S. & & L.I. & L.S. \\
\hline Ruim - Boa & 0,46 & 0,39 & 0,53 & 0,38 & 0,31 & 0,45 & 0,23 & 0,15 & 0,31 \\
\hline Negativa - Positiva & 0,35 & 0,27 & 0,43 & 0,31 & 0,22 & 0,38 & 0,16 & 0,09 & 0,23 \\
\hline Desfavorável - Favorável & 0,27 & 0,19 & 0,34 & 0,25 & 0,17 & 0,32 & 0,15 & 0,08 & 0,23 \\
\hline Não Gosto - Gosto & 0,34 & 0,26 & 0,42 & 0,28 & 0,21 & 0,36 & 0,16 & 0,08 & 0,24 \\
\hline
\end{tabular}

Fonte - Dados da pesquisa. Processamento efetuado por meio do Software Estatístico R, Versão 3.0.1.

Na Tabela 05 a seguir, tem-se a média e o a avaliação final dos três vídeos. intervalo de $95 \%$ de confiança para

Tabela 05 - média e intervalo de $95 \%$ de confiança para a avaliação final dos três vídeos.

\begin{tabular}{|c|c|c|c|c|c|c|c|c|c|}
\hline \multirow{3}{*}{ Variáveis } & \multicolumn{3}{|c|}{ ITAÚ } & \multicolumn{3}{|c|}{ " NEXTEL } & \multicolumn{3}{|c|}{ " BUDWEISER } \\
\hline & \multirow{2}{*}{ Média } & \multicolumn{2}{|c|}{ I.C - 95\% } & \multirow{2}{*}{ Média } & \multicolumn{2}{|c|}{ I.C - 95\% } & \multirow{2}{*}{ Média } & \multicolumn{2}{|c|}{ I.C - 95\% } \\
\hline & & L.I. & L.S. & & L.I. & L.S. & & L.I. & L.S. \\
\hline $\begin{array}{l}\text { Vale à pena compartilhar este vídeo } \\
\text { com outras pessoas. }\end{array}$ & 0,11 & 0,05 & 0,17 & 0,16 & 0,09 & 0,23 & 0,03 & $-0,04$ & 0,09 \\
\hline $\begin{array}{l}\text { Eu recomendaria este vídeo para } \\
\text { outras pessoas. }\end{array}$ & 0,17 & 0,10 & 0,22 & 0,17 & 0,10 & 0,24 & 0,01 & $-0,05$ & 0,08 \\
\hline
\end{tabular}

Fonte - Dados da pesquisa. Processamento efetuado por meio do Software Estatístico R, Versão 3.0.1.

Os indivíduos respondentes apresentaram uma tendência de concordarem moderadamente com o compartilhamento e de recomendarem para outras pessoas os vídeos do Itaú e da Nextel, porém, não concordaram, nem discordaram em compartilhar ou recomendar o vídeo da marca Budweiser, uma vez que, nesse caso, os intervalos de confiança interceptam o valor zero.

\subsection{Análise fatorial}

Na Tabela 06 a seguir encontra-se uma visão geral da adequação da solução fatorial dos construtos, apresentando os valores observados de KMO, VE, número de fatores (dimensões), Alfa de Cronbach, o total de itens em cada construto e as variáveis que foram retiradas para a adequação dos construtos e criação dos índices.

Dessa forma, pôde-se verificar que todos os construtos apresentaram valores de KMO dentro dos limites estabelecidos pela literatura (maiores que 0,50) e que as variâncias explicadas (VE) também ficaram acima do mínimo recomendado de 50\%. O menor Alfa de Cronbach foi de 0,85 , referente ao segundo construto "intensidade das emoções", indicando consistência interna dentro de cada construto. 
Tabela 06 - Adequação da Solução Fatorial dos Construtos

\begin{tabular}{|l|c|c|c|c|c|c|}
\hline Construto & KMO & VE & AC & $\begin{array}{c}\text { Número } \\
\text { de Fatores }\end{array}$ & $\begin{array}{c}\text { Total de } \\
\text { Variáveis }\end{array}$ & $\begin{array}{c}\text { Variáveis } \\
\text { Retiradas }\end{array}$ \\
\hline Intensidade das emoções & 0,933 & 0,64 & 0,95 e 0,85 & 2 & 18 & - \\
Intensidade do envolvimento & 0,827 & 0,83 & 0,93 & 1 & 5 & AE5* \\
Atitude em relação à marca & 0,845 & 0,81 & 0,92 & 1 & 4 & - \\
Atitude em relação ao anúncio & 0,858 & 0,84 & 0,93 & 1 & 4 & - \\
Propensão em compartilhar & 0,500 & 0,92 & 0,92 & 1 & 2 & - \\
\hline \hline
\end{tabular}

*Código da variável AE5 - "Fico chateado / entediado quando outras pessoas falam do produto".

Fonte - Dados da pesquisa. Processamento efetuado por meio do Software Estatístico R, Versão 3.0.1.

De acordo com (Hair Jr., et al. 2009), itens com cargas fatoriais abaixo de 0,50, devem ser retirados da análise fatorial, para um melhor ajuste do modelo, porém, uma vez efetuados os cálculos, nenhum item apresentou carga fatorial abaixo de 0,50. As comunalidades (quantidade total de variância que cada variável original compartilha com todas as outras variáveis incluídas na análise) também indicaram que os itens foram bem explicados pelos índices.

Para o construto "intensidade das emoções", foram encontrados 2 subconstrutos que foram denominados de "emoções negativas" e "emoções positivas".

\subsection{Comparações entre os índices obtidos} pelos vídeos

Em todos os construtos foram encontradas diferenças significativas entre os índices obtidos pelos três vídeos. Na Tabela 07 a seguir foram realizadas comparações múltiplas para identificar entre quais vídeos os índices se diferenciavam.

Tabela 07 - Comparações dos escores dos indicadores entre os vídeos.

\begin{tabular}{|c|c|c|c|c|c|c|c|}
\hline "Construto/Fator & "Vídeo & Mediana & E.P. & $\overline{\mathbf{1}^{\circ} \mathrm{Q}}$ & $\mathbf{2}^{\circ} \mathbf{Q}$ & $\mathbf{3}^{\circ} \mathrm{Q}$ & $\overline{\text { P-valor }}$ \\
\hline \multirow{3}{*}{$\begin{array}{l}\text { Intensidade das emoções } \\
\text { negativas }\end{array}$} & BUDWEISER & 19,30 & 1,08 & 2,73 & 13,28 & 29,25 & \multirow{3}{*}{0,000} \\
\hline & ITAÚ & 11,59 & 0,82 & 2,46 & 4,27 & 16,67 & \\
\hline & NEXTEL & 15,93 & 0,91 & 3,52 & 8,49 & 25,72 & \\
\hline \multirow{3}{*}{$\begin{array}{l}\text { Intensidade das emoções } \\
\text { positivas }\end{array}$} & BUDWEISER & 45,02 & 1,20 & 31,50 & 46,52 & 55,98 & \multirow{3}{*}{0,000} \\
\hline & ITAÚ & 57,99 & 1,04 & 48,18 & 58,52 & 69,04 & \\
\hline & NEXTEL & 58,83 & 1,11 & 49,53 & 60,05 & 70,99 & \\
\hline \multirow{3}{*}{ Intensidade do Envolvimento } & BUDWEISER & 39,48 & 1,82 & 11,91 & 36,98 & 61,98 & \multirow{3}{*}{0,000} \\
\hline & ITAÚ & 33,63 & 1,39 & 11,91 & 36,98 & 50,00 & \\
\hline & NEXTEL & 28,90 & 1,30 & 0,00 & 25,00 & 50,00 & \\
\hline \multirow{3}{*}{ Atitude em relação à marca } & BUDWEISER & 58,81 & 1,80 & 43,86 & 55,92 & 87,32 & \multirow{3}{*}{0,001} \\
\hline & ITAÚ & 52,37 & 1,64 & 31,50 & 50,00 & 69,25 & \\
\hline & NEXTEL & 53,69 & 1,42 & 43,82 & 50,00 & 68,82 & \\
\hline \multirow{3}{*}{ Atitude em relação ao anúncio } & BUDWEISER & 59,73 & 1,78 & 37,69 & 56,26 & 87,33 & \multirow{3}{*}{0,003} \\
\hline & ITAÚ & 67,75 & 1,76 & 50,00 & 75,00 & 100,00 & \\
\hline & NEXTEL & 64,97 & 1,75 & 50,00 & 68,76 & 100,00 & \\
\hline \multirow{3}{*}{ Propensão em compartilhar } & BUDWEISER & 51,62 & 1,74 & 25,00 & 50,00 & 75,00 & \multirow{3}{*}{0,021} \\
\hline & ITAÚ & 56,82 & 1,51 & 50,00 & 62,38 & 75,00 & \\
\hline & NEXTEL & 57,84 & 1,68 & 50,00 & 50,00 & 75,00 & \\
\hline
\end{tabular}

Fonte - Dados da pesquisa. Processamento efetuado por meio do Software Estatístico R, Versão 3.0.1.

E.P. = Erro-padrão, uma medida de precisão. $\mathrm{Q}=$ Quartil, uma medida de posição. 
Desta forma pode-se interpretar que:

- O valor mediano do índice de Emoções Negativas para o vídeo da Budweiser foi significativamente superior aos dos índices correspondentes obtidos pelos vídeos da Nextel e do Itaú, sendo que nesta variável, os valores medianos foram baixos para todos os vídeos.

- O valor mediano do índice de Emoções Positivas para o vídeo da Budweiser foi significativamente inferior aos dos vídeos da Nextel e do Itaú.

- O valor mediano do índice de Intensidade de Envolvimento para empresa Nextel foi significativamente inferior aos mesmos índices obtidos pelos vídeos do Itaú e da Budweiser.

- O valor mediano do índice de Atitude em relação a Marca para a Budweiser foi significativamente superior aos obtidos pelas marcas Itaú e Nextel.

- O valor mediano do índice de Atitude em relação ao Anúncio para a Budweiser foi significativamente inferior aos índices obtidos pelos vídeos do Itaú e da Nextel.

- O valor mediano do índice de Propensão em compartilhar do vídeo da Budweiser foi significativamente inferior aos mesmos índices obtidos pelos vídeos da Nextel e do Itaú.

\subsection{Fatores que influenciam a tendência ao compartilhamento dos vídeos publicitários}

Esta variável foi aferida pelo índice Propensão em Compartilhar, que varia de 0100 , sendo que quanto maior o valor do índice, maior a chance do individuo compartilhar e recomendar o vídeo. Para verificar os fatores que influenciam no índice Propensão em Compartilhar foi utilizada a Análise de Regressão via QuaseVerosimilhança (WEDDERBURN, 1974; McCULLAGH \& NELDER, 1989) com função de variância constante e função de ligação identidade.

\subsubsection{Teste de correlação entre os índices}

Em uma primeira etapa buscou-se verificar se haveria correlação entre os cinco índices que expressavam os fatores que influenciariam os espectadores dos vídeos publicitários a compartilharem-nos (ou não) com terceiros via Internet após os assistirem. 
Tabela 08 - Correlação entre os índices

\begin{tabular}{|c|c|c|c|c|c|}
\hline Índices & EN & $\mathbf{E P}$ & IE & ARM & ARA \\
\hline Intensidade das Emoções Negativas - EN & 1 & & & & \\
\hline Intensidade das Emoções Positivas - EP & 0,08 & 1 & & & \\
\hline Intensidade do Envolvimento - IE & 0,10 & $0,27 *$ & 1 & & \\
\hline Atitude em Relação à Marca - ARM & 0,03 & $0,24 *$ & $0,46^{*}$ & 1 & \\
\hline Atitude em Relação ao Anúncio - ARA & (-) $0,16^{*}$ & $0,46^{*}$ & $0,31 *$ & $0,51 *$ & 1 \\
\hline
\end{tabular}

Fonte - Dados da pesquisa. Processamento efetuado por meio do Software Estatístico R, Versão 3.0.1.

* Correlação significativa (valor $\mathrm{p}<0,05$ )

Assim, conforme a Tabela 08, as correlações entre variáveis que apresentaram significância estatística (valor $\mathrm{p}<0,05$ ) foram:

\section{Atitude em Relação ao Anúncio - ARA} demonstrou estar positivamente correlacionada com Atitude em Relação à Marca - ARM (0,51); com a Intensidade das Emoções Positivas - EP (0,46); com a Intensidade do Envolvimento - IE $(0,31) \mathrm{e}$ negativamente correlacionada com a Intensidade das Emoções Negativas - EM ($0,16)$.

Atitude em Relação à Marca - ARM apresentou correlação positiva e significativa com Intensidade do Envolvimento - IE $(0,46)$ e com Intensidade das Emoções Positivas EP $(0,24)$.

Intensidade do Envolvimento - IE $(0,46)$ apresentou-se positivamente correlacionada com a Intensidade das Emoções Positivas $E P(0,27)$.
Note-se que todas essas correlações encontradas também fazem sentido em termos intuitivos.

\section{VERIFICAÇÃO DAS HIPÓTESES}

Foram testadas estatisticamente cinco hipóteses de trabalho:

$\mathbf{H}_{1}$ - A atitude do espectador em relação à marca é estatisticamente significativa para predizer a propensão deste em compartilhar vídeos publicitários do YouTube.

$\mathbf{H}_{2}$ - A atitude do espectador em relação ao anúncio é estatisticamente significativa para predizer a propensão deste em compartilhar vídeos publicitários do YouTube.

$\mathbf{H}_{3}$ - A intensidade de envolvimento do espectador com o vídeo é estatisticamente significativa para predizer a propensão deste em compartilhar vídeos publicitários do YouTube.

$\mathbf{H}_{4}$ - O índice de emoções positivas do espectador é estatisticamente significativo 
para predizer a propensão deste em compartilhar vídeos publicitários do YouTube. $\mathbf{H}_{5}$ - O índice de emoções negativas do espectador é estatisticamente significativo para predizer a não-propensão deste em compartilhar vídeos publicitários do YouTube.

Os achados da pesquisa, após a realização dos respectivos procedimentos operacionais e cálculos estatísticos, comprovaram quatro das cinco hipóteses de trabalho formuladas, logrando responder positivamente nessas quatro hipóteses as indagações básicas que nortearam a realização deste trabalho.

Os testes estatísticos efetuados nas hipóteses: $\mathbf{H}_{2}, \mathbf{H}_{3}, \mathbf{H}_{4}, \mathbf{H}_{5}$ conseguiram validálas integralmente no nível de significância estatística pretendido, o mesmo não ocorrendo no que se refere à $\mathbf{H}_{\mathbf{1}}$. Os valores de teste encontrados em: $\mathbf{H}_{2}(0,28), \mathbf{H}_{3}(0,26)$ e $\mathbf{H}_{4}(0,45)$ situaram-se em patamares relativamente mais elevados do que seu correspondente mais modesto e com sinal negativo (-) 0,19 obtido para $\mathbf{H}_{5}$.

No âmbito prático, os achados empíricos, resumidos na Tabela 09, que será apresentada a seguir, corroboraram as principais conclusões a que também já haviam chegado alguns artigos acadêmicos e relatórios de pesquisas internacionais sobre o tema, reportando haver uma relação positiva e direta entre a intensidade do envolvimento dos espectadores de vídeos publicitários do YouTube, em especial, das atitudes e das emoções desses espectadores com a propensão dos mesmos em compartilhá-los com terceiros via Internet.

Tabela 09 - Resumo dos testes de hipóteses da pesquisa

\begin{tabular}{|c|c|c|c|c|}
\hline Hipóteses & Tipo do Teste & $\begin{array}{c}\text { Valor Beta } \\
\text { Encontrado }\end{array}$ & $\begin{array}{c}\text { P-valor significativo? } \\
\text { Sim / Não }\end{array}$ & Resultado do Teste \\
\hline $\mathbf{H}_{1}$ & $\begin{array}{c}\text { Regressão Linear } \\
\text { Stepwise }\end{array}$ & 0,05 & $\begin{array}{l}0,116 \\
\text { Não }\end{array}$ & Hipótese rejeitada \\
\hline $\mathbf{H}_{2}$ & $\begin{array}{c}\text { Regressão Linear } \\
\text { Stepwise }\end{array}$ & 0,28 & $\begin{array}{l}0,000 \\
\text { Sim }\end{array}$ & Hipótese aceita \\
\hline $\mathbf{H}_{3}$ & $\begin{array}{c}\text { Regressão Linear } \\
\text { Stepwise }\end{array}$ & 0,26 & $\begin{array}{l}0,000 \\
\text { Sim }\end{array}$ & Hipótese aceita \\
\hline $\mathbf{H}_{4}$ & $\begin{array}{c}\text { Regressão Linear } \\
\text { Stepwise }\end{array}$ & 0,45 & $\begin{array}{l}0,000 \\
\text { Sim }\end{array}$ & Hipótese aceita \\
\hline $\mathbf{H}_{5}$ & $\begin{array}{c}\text { Regressão Linear } \\
\text { Stepwise }\end{array}$ & (-) 0,19 & $\begin{array}{l}0,000 \\
\text { Sim }\end{array}$ & Hipótese aceita \\
\hline
\end{tabular}

Fonte - Dados da pesquisa. Processamento efetuado por meio do Software Estatístico R, Versão 3.0.1.

$\mathrm{R}^{2}=0,502$ - Variabilidade do índice "propensão em compartilhar” explicada pelas variáveis estudadas. 
Conseguiu-se provar, portanto, no presente trabalho, com razoável base de fundamentação estatística, que existe uma convergência e compatibilidade estatística entre os índices construídos a partir dos valores brutos das variáveis estudadas colhidos originalmente dos respondentes em uma escala de cinco pontos do tipo Likert.

\section{CONSIDERAÇÕES FINAIS}

Em um ambiente de negócios cada vez mais competitivo, o marketing viral é uma ferramenta eficaz, que incentiva os indivíduos a consumirem determinadas marcas, produtos ou serviços anunciados como resultado das mensagens que os atingiram e as repassarem a terceiros. O objetivo do marketing viral é, portanto, duplo: incentivar o consumo e o compartilhamento de experiências.

Este estudo revelou que a existência de emoções positivas é essencial para a decisão do compartilhamento de um vídeo publicitário viral, os consumidores ficam mais receptivos a transmiti-lo ao seu grupo social.

A atitude em relação à marca quando associada a emoções positivas são mais bem recebidas pelo consumidor, caso acontecido com a marca Budweiser, que foi a mais bem avaliada entre os entrevistados, porém seu anúncio foi o de pior avaliação, quando as emoções negativas, apesar de não aparecerem de forma exponencial, ficaram próximas ao nível de aceitação.
As emoções positivas são responsáveis pela influência dos anúncios nos consumidores, a pesquisa mostrou que os anúncios contendo maiores índices de emoções positivas despertadas foram os que apresentaram maiores índices de compartilhamento, no caso da Nextel e do Itaú, já o anúncio da Budweiser, por conter um contexto de luta e suspense não obteve a mesma avaliação.

De Bruyn \& Lilien (2008) e Dobele et al. (2007), em seus estudos, também mostraram que emoções positivas são fatores importantes no compartilhamento dos vídeos, porém com uma diferença, nos artigos mencionados foi identificada a "surpresa" como uma das principais emoções para o compartilhamento, o que não ocorreu neste estudo. Uma possível explicação para a diferença nos resultados é o fato de se tratar de uma amostragem nãoprobabilística, impedindo a generalização dos resultados.

Em estudos futuros deve-se procurar aperfeiçoar as definições das emoções e medir mais intensamente o impacto do marketing viral da indústria da publicidade sobre os consumidores. Este estudo identificou algumas formas sobre como o fenômeno viral afeta o comportamento do indivíduo para o compartilhamento de vídeos publicitários em relação às emoções despertadas, no entanto, há outra questão importante, quais emoções são despertadas ou associadas a determinadas marcas de produtos e serviços? Estudos 
futuros poderão investigar os efeitos das emoções sobre as marcas nos âmbitos: atitudinal, cognitivo ou comportamental. O fenômeno do marketing viral oferece uma oportunidade para os pesquisadores avaliarem os efeitos das emoções provocadas nos consumidores de várias maneiras. Outras pesquisas envolvendo o marketing e $\mathrm{o}$ consumo de determinadas categorias de marcas, produtos e de anúncios, poderiam fornecer uma visão mais aprofundada das motivações e dos impactos da publicidade viral.

Este estudo apresentou definições empiricamente testadas das emoções despertadas em relação a vídeos de publicidade viral. Acadêmicos e profissionais poderão desenvolver novos trabalhos explorando esta nova área de grande importância na estratégia das empresas fornecedoras. Com as grandes mudanças tecnológicas e culturais que se desenham no horizonte da indústria da publicidade, o marketing viral será uma força cada vez mais importante num futuro próximo no cenário do consumo de massa.

\section{REFERÊNCIAS}

ALMEIDA, M. I. S.; COELHO, R. L. F.; TETE, M. F. Perspectiva evolutiva do marketing viral: um ensaio sobre sua fundamentação teórica e alternativas para futuros trabalhos. In: ENCONTRO DA ANPAD, 35., 2011, Rio de Janeiro. Anais... Rio de Janeiro: ANPAD, 2011.

ANDRADE, J.; MAZZON, J. A.; KATZ, S. Você viu o vídeo do Ronaldinho? Uma reflexão a respeito da associação entre marcas e celebridade e o uso do marketing viral como ferramenta de comunicação de marketing. In: EnANPAD, 30., 2006, Salvador. Anais... Salvador: ANPAD, 2006.

BAGOZZI, R. P.; GOPINATH, M.; NYER, P. U. The Role of Emotions in Marketing, Journal of the Academy of Marketing Science, v. 27 n. 2, p. 184-206, Spring 1999.

BARICHELLO, E. M. M. R.; OLIVEIRA, C. C. O marketing viral como estratégia publicitária nas novas ambiências midiáticas. Revista Em Questão, Porto Alegre, v.16, n. 1, p. 29-44, jan/jun., 2010.

\section{BORROFF, R. Viral marketing. Precision} Marketing, 20, 12. November, 2000.

\section{BRAINSTORM9. Os 10 comerciais} brasileiros mais populares no YouTube em 2012. Disponível em: <http://www.brainstorm9.com.br/33255/adver tising/os-10-comerciais-brasileiros-maispopulares-no-YouTube-em-2012> Acesso em: 11 de set. 2013.

BRODIN, O. Les communautés virtuelles: Un potential marketing encore peu exploré.

Décisions Marketing, 21, 47-56

(September-December). 2000.

CERVO, A. L., BERVIAN, P. A.; DA

SILVA, R. Metodologia científica. $6^{\mathrm{a}}$ ed. São Paulo: Pearson Prentice Hall, 2007.

De BRUYN, A.; LILIEN, G. A multi-stage model of word-of-mouth influence through viral marketing. International Journal of Research in Marketing, [S.I.], v. 25, n. 3, p. 151-163, set. 2008.

DERBAIX, C.; VANHAMME, J. Inducing word-of-mouth by eliciting surprise: a pilot investigation. Journal of Economic

Psychology, v.24, n.1, p. 99-107, 2003.

DOBELE, A.; LINDGREEN A.;

BEVERLAND, M.; VANHAMME, J.; van WIJK, R. Why pass on viral messages? Because they connect emotionally. Science 
Direct. Business Horizons, v.50, n.1, p. 291304, 2007.

ECKLER P.; BOLLS, P. Spreading the virus: emotional tone of viral advertising and its effect on forwarding intentions and attitudes.

Journal of Interactive Advertising, v.11, p. 1-11, 2011.

EFRON, B.; TIBSHIRANI, R. J. An

Introduction to the Bootstrap. Chapman \& Hall, 1993.

EFROYMSON, M. A. Multiple regression analysis: Mathematical Methods for Digital Computers, 1960.

GRUEN, T. W., OSMONBEKOV, T., \& CZAPLEWSKI, A. J. eWOM: The impact of customer-to-customer online know-how exchange on customer value and loyalty. Journal of Business Research, 59(4), 449-456. 2006.

HAIR Jr., J. F., ANDERSON, R. E., TATHAM, R. L. \& BLACK, W. C. Análise Multivariada de Dados. Porto Alegre. Bookman, 2009.

HARVEY, C. G.; STEWART, D. B.; EWING, M. T. Forward or delete: what drives peer-to-peer message propagation across social networks? Journal of Consumer Behaviour, v.10, p. 365-372, 2011.

HELM, S. Viral marketing — Establishing customer relationships by word-of-mouse.

Electronic Markets, 10(3), p. 158-161. 2000.

HOLLANDER, M. \& WOLFE, D. A.

Nonparametric Statistical Methods. New

York. John Wiley \& Sons, 1999.

KINLEY, T. R.; JOSIAM, B. M.; LOCKETT, F. Shopping behavior and the involvement construct. Journal of Fashion Marketing and Management, v. 14, n. 4, p. 562-575, 2010.

LAUDON, K. C., \& TRAVER, C. G. Ecommerce: Business, technology, society. Boston: Addison-Wesley. 2001.
LAZARUS, R. S. Emotion and Adaptation, New York: Oxford University Press, 1991.

LESTER, E. P. Finding the path to signification: undressing a Nissan Pathfinder direct mail package. In: FRITH, Katherine T. (Ed.). Undressing the ad. Reading the culture in advertising. New York (EUA): Peter Lang, p. 19-34. 1998.

\section{LINDGREEN, A.; VANHAMME, J. Viral} marketing: the use of surprise in advances in electronic marketing. Hershey, PA: Idea Group Publishing, p. 122-138. 2005.

LINDSTROM, M. Essential elements of viral video success. [s.1.]. Advertising Age, 2009.

MALHOTRA, N. Pesquisa de marketing: foco na decisão. $3^{\text {a }}$ ed. São Paulo: Pearson Prentice Hall, 2011.

MARCONI, M. A.; LAKATOS, E. M. Metodologia científica. $5^{a}$ ed. São Paulo: Atlas, 2011.

McCULLAGH P. \& NELDER, J. A. Generalized Linear Models. London. Chapman and Hall, 1989.

MINGOTI, S. A. Análise de Dados Através de Métodos de Estatística Multivariada: Uma Abordagem Aplicada. Belo Horizonte. UFMG, 2007.

MONNERAT, R. M. A publicidade pelo avesso: propaganda e publicidade, ideologias e mitos e a expressão da ideia: o processo de criação da palavra publicitária. Niterói: Editora EdUff, 2003.

OATLEY, K., JENKINS, J. M. Understanding emotions. Boston: Blackwell Publishers, 1996.

PHELPS, J. et al. Viral marketing or electronic word of mouth advertising: examiningconsumer responses and motivations to pass along email. Journal of Advertising Research, [S.I.], v. 44, n. 4, p. 333-348, dez. 2004. 
PORTER, L.; GOLAN, G. J. From subservient chickens to brawny men: a comparison ofviral advertising to television advertising. Journal of Interactive Advertising, v.6, n. 2, p. 26-33, 2006.

SAMARA, B. S.; BARROS, J. C. Pesquisa de marketing: conceitos e metodologia. $4^{\mathrm{a}}$ ed. São Paulo: Pearson Prentice Hall, 2007.

SANT`ANNA, A.; JÚNIOR, I. R.; GARCIA, L. F. D. Propaganda: teoria, técnica e prática. $8^{\mathrm{a}}$ ed. São Paulo: Cengage Learnig, 2009.

SHETH, J. N. Impact of Emerging markets on marketing: rethinking existing perspectives and practices. Journal of Marketing, v. 75, n. 4, p. 166-182. 2011.

STANBOULI, K. Marketing viral et publicité. [s.l.]: Revue Française du Marketing, p. 97-107. 2003.
SUBRAMANI, M. R.; RAJAGOPALAN, B. Knowledge-sharing and influence in online social networks via viral marketing.

Communications of the ACM, v. 46, n.12, p. 300-307, 2003.

VENKATESAN, R., FARRIS, P. W., GUISSONI, L. A. \& NEVES, M. F.

(Un)Conventional channels: consumer brand marketing in emerging markets In: Harvard Business School - Theory \& Practice in Marketing (TPM) Conference, Boston, 2012.

WEDDEBURN, R. W. M. Quasilikelihood functions, generalized linear models and the Gauss-Newton method. Biometrika, p. 439-447. 1974.

WEINBERG, T. As novas regras da comunidade: marketing na mídia social. Rio de Janeiro: Alta Books, 2010. 